\title{
PERANCANGAN PROTOTIPE SISTEM PENGATURAN LAMPU DAN PINTU GERBANG MENGGUNAKAN SMS (SHORT MESSAGE SERVICE) BERBASIS MIKROKONTROLER ATMEGA 8535
}

\author{
Asep Najmurrokhman dan Tedi Muslim
}

\begin{abstract}
ABSTRAK
Hampir semua orang memiliki telepon seluler untuk berkomunikasi dengan orang lain baik melalui telepon langsung atau melalui pesan singkat. Dalam makalah ini dipaparkan pemanfaatan telepon seluler dalam pengaturan lampu dan pintu gerbang rumah secara otomatis. Prototipe yang dirancang tersusun oleh dua buah telepon seluler, sebuah mikrokontroler, motor DC untuk menggerakkan pintu gerbang, dan lampu pijar. Dua buah telepon seluler berfungsi masing-masing sebagai server di rumah dan yang dipegang oleh pengguna. Sistemnya dikendalikan oleh mikrokontroler sebagai pengendali utamanya. Proses pengaturan pintu gerbang dan lampu dilakukan melalui pesan singkat yang dikirim dari telepon seluler pengguna ke telepon seluler server yang ditempatkan di rumah. Kemudian isi pesan tersebut diteruskan ke mikrokontroler dan selanjutnya mikrokontroler mengirimkan sinyal ke driver yang bersesuaian dengan isi pesan tersebut. Pengujian memperlihatkan lampu dan pintu gerbang dapat diatur sesuai dengan perintah yang diberikan melalui pesan singkat.
\end{abstract}

Kata Kunci : mikrokontroler, pesan singkat, pengaturan lampu, pengaturan pintu gerbang, telepon seluler (ponsel)

\begin{abstract}
Nowadays, everyone utilizes cellular phone to communicate each other by talking directly or by sending a short message. In this paper, we develop a prototype of lamp and gate automatic control system based on usage of short message services provided by communication network provider. This prototype consist of two cellular phones, microcontroller, DC motor driver to deliver an open/closed action of gate, and bulb. Both cellular phones are provided as controller at user side and server at the other side, respectively. Open/closed of gate and turn on/off of bulb are controlled by sending a short message from controller to server placed at home. A short message is then decoded by a microcontroller being an appropriate instruction. The experiment shows that a bulb and gate could be controlled according to instruction delivered by a short message.
\end{abstract}

Keywords: microcontroller, short message, bulb control, gate control, cellular phone.

\section{PENDAHULUAN}

Pada saat ini dunia teknologi telekomunikasi berkembang sangat pesat dan berperan penting untuk memudahkan komunikasi antar manusia dalam kehidupan sehari-harinya. Dengan semakin berkembangnya teknologi tersebut maka jarak tidak lagi menjadi halangan untuk senantiasa berhubungan atau berkomunikasi. Salah satu alat telekomunikasi pada saat ini yang paling diminati adalah telepon seluler. Selain mudah mengoperasikannya, alat ini juga sangat praktis dan mudah dibawa kemana-mana, dengan berbagai merek dan model dapat dijumpai ditoko-toko telepon seluler. Adapun salah satu fitur favorit pada saat ini yang terdapat dalam telepon seluler adalah layanan pesan singkat atau SMS (Short Message Service). Penggunaan fitur SMS ini di kalangan masyarakat banyak terbatas sebagai sarana untuk berkomunikasi lewat teks.

Untuk memaksimalkan penggunaan ponsel dalam kehidupan manusia, penelitian ini mengkaji penggunaan pesan singkat dalam pengaturan peralatan di rumah, misalnya lampu dan pintu gerbang. Tujuan dari penelitian ini adalah membuat prototipe sistem pengaturan peralatan di rumah menggunakan pesan singkat ponsel. Dalam penelitian ini dilakukan analisis sistem kerja dari penggunaan pesan singkat untuk mengatur buka tutup pintu gerbang dan nyala mati lampu pijar. Karena implementasi sistemnya menggunakan jaringan publik, maka kinerja sistem akan sangat bergantung terhadap kondisi jaringan tersebut. Selain itu, dalam penelitian awal ini perintah untuk mengatur alat dilakukan secara sekuensial artinya 
tidak bisa dilakukan secara bersamaan dan status alat simulasi dalam keadaan tidak aktif (off).

\section{DASAR TEORI}

\subsection{KONSEP DASAR SMS (SHORT MESAGGE SERVICE)}

GSM (Global System for Mobile Communication) adalah standar komunikasi seluler digital yang bekerja pada frekuensi $900 \mathrm{MHz}$. Stallings (2005) mengungkapkan bahwa standar ini dikembangkan oleh gabungan negara-negara Eropa dan digunakan secara komersial pada tahun 1991 dan memiliki spesifikasi teknis sebagai berikut: Modulasi yang digunakan GMSK (0.3 Gaussian Filter), channel spacing $200 \mathrm{KHz}$, channel bit rate 270.833 Kbps, number of channel 124 (8 users/channel), metode duplex yang digunakan FDD, multiple akses metode TDMA/ FDM.

Menurut sumber di internet [Wikipedia (2011)], fase awal implementasi GSM pada tahun 1991 baru memperkenalkan layanan suara. Sekitar tahun 1995-an, fitur lain yang dimiliki teknologi GSM mencakup layanan pesan singkat atau dikenal dengan SMS, suara (voice) dan voice-mail service/box [Selian (2001)]. Di Indonesia, Soesetijo (2008) menyatakan bahwa teknologi GSM pertama kali hadir pada tahun 1993 dan SMS mulai beredar di udara pada tahun 1997, namun itu pun masih beredar pada ponsel intra-operator, belum bisa digunakan antar ponsel yang beda operator. Baru pada tahun 1999, dibuka interkoneksi antar ketiga operator GSM yaitu Satelindo, Telkomsel dan Excelcomindo.

Teknologi yang digunakan dari pengiriman SMS intra operator adalah store and forward service, yang berarti SMS yang dikirim akan disimpan sementara di server SMS Center dan kemudian dialihkan ke nomor tujuan. Jadi sebenarnya kita mengirim SMS ke nomornya SMS Center sesuai nomor yang disetting pada menu service center message pada setiap ponsel. Kemudian oleh SMS Center akan diteruskan ke nomor tujuan, setelah dicek di HLR (home location register) untuk menentukan apakah ponsel aktif atau tidak. Apabila aktif, pesan SMS akan diteruskan ke nomor tujuan. Sedangkan apabila tidak aktif, akan sementara disimpan di server sampai waktu tertentu. Kondisi aktif pun sebetulnya tidak menjamin SMS bisa sampai dengan cepat, itu pun masih tergantung dengan bandwidth jaringan yang digunakan untuk interkoneksi antar server SMS Center operator.

Teknologi yang digunakan dari pengiriman SMS antar operator adalah dengan kerjasama interkoneksi server SMS Center-nya masingmasing operator. Interkoneksi SMS center bisa dilakukan dengan dua cara yaitu melewati koneksi SMS gateway via jaringan internet/IP network atau langsung interface antar SMS Center operator.

\subsection{Konsep Dasar PDU (Protocol Data Unit)}

Protocol Data Unit (PDU) adalah sederetan bilangan heksadesimal, yang mencerminkan bahasa I/O pada ponsel, artinya data yang mengalir pada SMS berbentuk PDU. Bilangan heksadesimal terdiri dari simbol angka dan huruf dengan urutan sebagai berikut $0,1,2,3,4,5,6,7,8,9, A, B, C, D, E, F$. Berdasarkan format PDU setiap ponsel, isi SMS dapat diatur sendiri oleh pengelola. Badan yang mendefinisikan standar penulisan dan pengkodean SMS ini adalah The European Telecommunications Standards Institute (ETSI). Ada perangkat lunak yang dapat mengkonversi PDU ke teks dan sebaliknya yang bernama Protocol Data Unit (PDU) Spy.

\subsection{Konsep Dasar Perintah AT (AT Command)}

$A T$ Command adalah kode instruksi yang digunakan untuk melakukan komunikasi dengan ponsel. Ponsel pada dasarnya adalah modem, sehingga AT Command pun berlaku pada modem. Dengan menggunakan kabel data yang tersedia pada masing-masing jenis merek ponsel, kita dapat berkomunikasi dengan ponsel melalui komputer. Keuntungan menggunakan perintah AT Command adalah dapat mengotomatisasi tugas pada ponsel mulai dari penerimaan sampai dengan pengiriman balasan SMS. Untuk mengotomatisasi tugas pada ponsel, maka diperlukan juga bahasa pemrograman yang dapat berkomunikasi dengan port COM pada komputer. Pada penelitian ini, AT Command yang digunakan adalah AT Command Siemens Mobile Phone S35i, C35i, M35i.

\section{KOMPONEN PENDUKUNG}

\subsection{Mikrokontroler ATMega8535}

Sebuah tipe mikrokontroler yang disebut Mikrokontroler AVR (Alf and Vegard's RISC) memiliki arsitektur RISC 8 bit, dimana semua instruksi dikemas dalam kode 16-bit (16 bits word) dan sebagian besar instruksi dieksekusi dalam 1 siklus clock, berbeda dengan instruksi MCS51 yang membutuhkan 12 siklus clock. AVR berteknologi RISC (Reduction Instruction Set Computing), sedangkan seri MCS51 berteknologi CISC (Complex Instruction Set Computing). Secara umum, AVR dapat dikelompokkan dalam 4 kelas, yaitu keluarga Attiny, AT90Sxx, ATMega, dan AT86RFxx. Pada dasarnya yang membedakan masing-masing kelas adalah memori, peripheral dan fungsinya. Dari segi arsitektur dan instruksi yang digunakan, keempat level bisa dikatakan hampir sama. Oleh karena itu, dipergunakan salah satu AVR produk Atmel, yaitu ATMega8535. Pemrograman pada chip ini dapat menggunakan simulasi yang terdapat pada perangkat lunak Code Vision AVR atau langsung ke perangkat keras. Selain mudah didapat dan murah, ATMega8535 
juga memiliki fasilitas ADC didalamnya yang berguna dalam pengolahan sinyal analog dari sensor. Arsitektur ATMega8535 diperlihatkan pada Gambar 1.

\subsection{Arsitektur ATMega8535}

Arsitektur ATMega8535 memiliki bagian sebagai berikut :

a) Saluran I/O sebanyak 32 buah, yaitu Port A, Port B, Port C, dan Port D

b) ADC 10 bit sebanyak 8 saluran

c) Tiga buah timer/counter dengan kemampuan pembandingan

d) CPU yang terdiri atas 32 buah register

e) Watchdog Timer dengan osilator didalamnya

f) SRAM sebesar 512 byte

g) Memory flash sebesar $8 \mathrm{~kb}$ dengan kemampuan read while write

h) Unit interupsi internal dan eksternal

i) Port antarmuka SPI

j) EEPROM sebesar 512 byte yang dapat diprogram saat operasi

k) Antarmuka komparator analog

1) Port USART untuk komunikasi serial

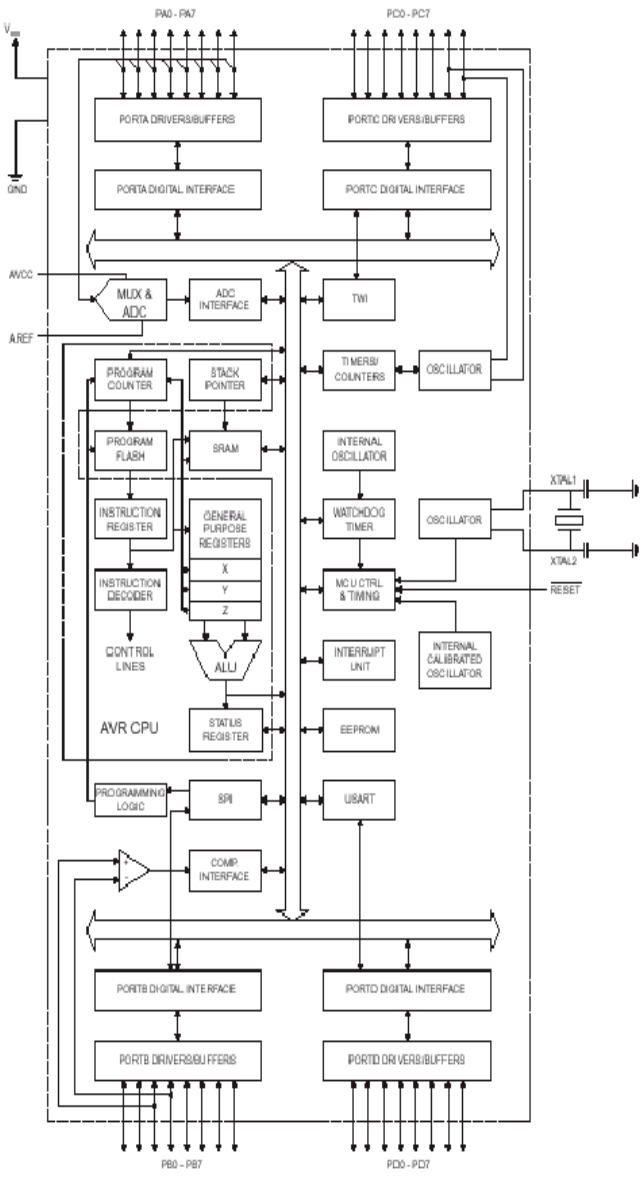

Gambar 1. Arsitektur Mikrokontroler ATMega8535

\subsection{Fitur ATMega8535}

Kemampuan dari ATMega8535 adalah sebagai berikut :

a) Sistem mikroprosesor 8 bit berbasis RISC dengan kecepatan maksimal $16 \mathrm{Mhz}$

b) Kapabilitas memori flash 8kb, SRAM sebesar 512 byte, dan EEPROM (Electrically Erasable Programmable Read Only Memory) sebesar 512 byte

c) ADC internal dengan fasilitas 10 bit sebanyak 8 channel

d) Port komunikasi serial (USART) dengan kecepatan maksimal 2,5 Mbps

e) Enam pilihan mode sleep menghemat penggunaan daya listrik

\subsection{Konfigurasi Pin ATMega8535}

Konfigurasi pin ATMega8535 terdapat pada gambar 2. Secara fungsional konfigurasi pin ATMega8535 sebagai berikut :

a) VCC merupakan pin yang berfungsi sebagai pin masukan catu daya

b) GND merupakan pin ground

c) Port A (PA0..PA7) merupakan pin I/O dua arah dan pin masukan ADC

d) Port B (PB0..PB7) merupakan pin I/O dua arah dan pin fungsi khusus, yaitu Timer/Counter, komparator analog dan SPI

e) Port C (PC0..PC7) merupakan pin I/O dua arah dan pin fungsi khusus yaitu TWI, komparator analog, dan Timer Oscillator

f) Port D (PD0..PD7) merupakan pin I/O dua arah dan pin fungsi khusus, yaitu komparator analog, interupsi eksternal, dan komunikasi serial

g) RESET merupakan pin yang digunakan untuk me-reset mikrokontroler

h) XTAL1 dan XTAL2 merupakan pin masukan clock eksternal

i) AVCC merupakan pin masukan tegangan untuk ADC

j) AREF merupakan pin masukan tegangan referensi ADC

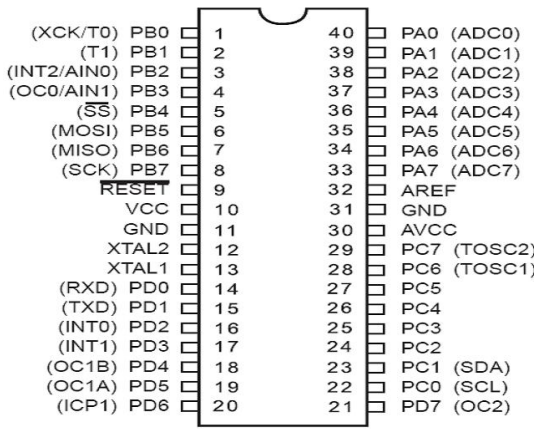

Gambar 2. Konfigurasi Pin Mikrokontroler ATMega8535 


\subsection{KOMUNIKASI SERIAL RS232}

Komunikasi data serial sangat berbeda dengan format pemindahan data paralel. Disini, pengiriman bit-bit tidak dilakukan sekaligus melalui saluran paralel, tetapi setiap bit dikirimkan satu persatu melalui saluran tunggal. Dalam pengiriman data secara serial harus ada sinkronisasi atau penyesuaian antara pengirim dan penerima agar data yang dikirmkan dapat diterima dengan tepat dan benar oleh penerima. Salah satu mode transmisi dalam komunikasi serial adalah mode asynchronous. Transmisi serial mode ini digunakan apabila pengiriman data dilakukan satu karakter tiap pengiriman. Antara satu karakter dengan yang lainnya tidak ada waktu antara yang tetap. Karakter dapat dikirimkan sekaligus ataupun beberapa karakter kemudian berhenti untuk waktu yang tidak tentu, kemudian dikirimkan sisanya. Dengan demikian bit-bit data ini dikirimkan dengan periode yang acak sehingga pada sisi penerima data akan diterima kapan saja. Adapun sinkronisasi yang terjadi pada mode transmisi ini adalah dengan memberikan bit-bit penanda awal dari data dan penanda akhir dari data pada sisi pengirim maupun dari sisi penerima.

Format data komunikasi serial terdiri dari parameter-parameter yang dipakai untuk menentukan bentuk data serial yang dikomunikasikan, dimana elemen-elemennya terdiri dari :

a) Kecepatan mobilisasi data per bit (baud rate)

b) Jumlah bit data per karakter (data length)

c) Parity yang digunakan

d) Jumlah stop bit dan start bit

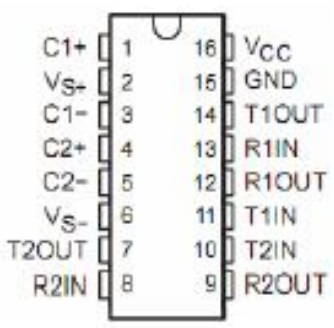

\section{Gambar 3. IC MAX232}

RS232 sebagai komunikasi serial mempunyai 9 pin yang memiliki fungsi masing-masing. Pin yang biasa digunakan adalah pin 2 sebagai received data, pin 3 sebagai transmited data, dan pin 5 sebagai ground signal. Karakteristik elektrik dari RS232 adalah sebagi berikut :

a) Space (logic 0) mempunyai level tegangan sebesar $+3 \mathrm{~s} / \mathrm{d}+25$ Volt

b) Mark (logic 1) mempunyai level tegangan sebesar -3 s/d -25Volt

c) Level tegangan antara $+3 \mathrm{~s} / \mathrm{d}-3$ Volt tidak terdefinisikan d) Arus yang melalui rangkaian tidak boleh melebihi dari $500 \mathrm{~mA}$, ini dibutuhkan agar sistem yang dibangun bekerja dengan akurat

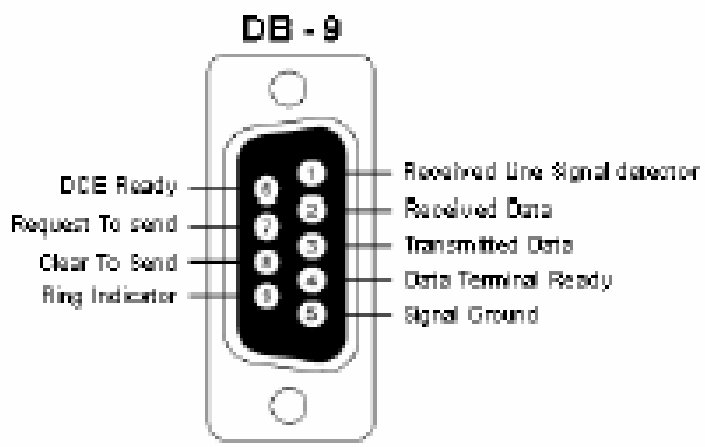

Gambar 4. Konektor DB-9

Tabel 1. Susunan Pin pada Konektor DB-9

\begin{tabular}{|c|c|}
\hline \multicolumn{2}{|c|}{ RS 232 Pin Assignments (DB9 PC Signal Set) } \\
\hline Pin 1 & $\begin{array}{c}\text { Received Line Signal Detector } \\
\text { (Data Carrier Detect) }\end{array}$ \\
\hline Pin 2 & Received Data \\
\hline Pin 3 & Transmit Data \\
\hline Pin 4 & Data Terminal Ready \\
\hline Pin 5 & Signal Ground \\
\hline Pin 6 & Data Set Ready \\
\hline Pin 7 & Request To Send \\
\hline Pin 8 & Clear To Send \\
\hline Pin 9 & Ring Indicator \\
\hline
\end{tabular}

\section{PERANCANGAN ALAT}

Diagram blok prototipe yang dirancang diperlihatkan pada gambar 6 .

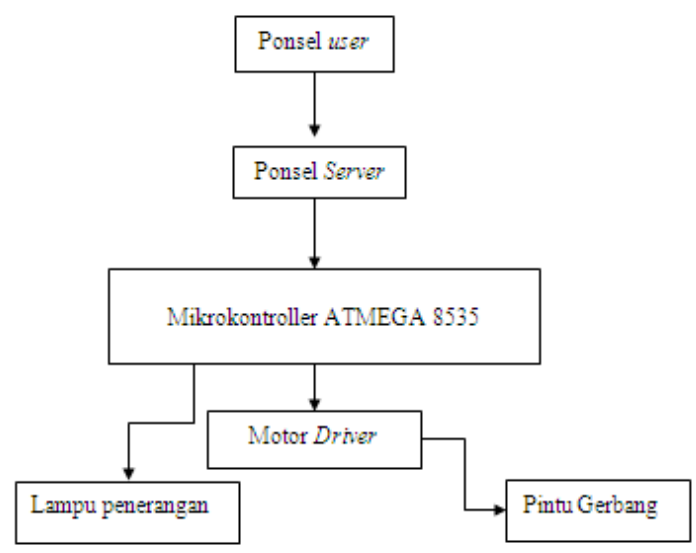

Gambar 6. Diagram blok sistem

Cara kerja dari prototipe yang dibuat ini adalah dengan cara mengolah pesan SMS berupa permintaan data yang dikirim dari ponsel user ke 
sebuah ponsel server yang telah terhubung dengan mikrokontroler ATMega8535, dimana isi pesan tersebut akan diolah/diproses oleh mikrokontroler sehingga dapat menghidupkan atau mematikan lampu atau membuka atau menutup pintu gerbang.

\subsection{Sistem Pengiriman SMS}

Proses pengiriman pesan dari satu ponsel ke ponsel lain merupakan proses prosedural secara bertahap. Saat menekan tombol send untuk mengirimkan SMS dari ponsel, proses yang terjadi adalah mengkodekan pesan dengan format $\mathrm{MO}$ (Mobile Originated) ke SMS Center (SMSC). Informasi yang terkandung dalam MO adalah:

a) Service Center Address (SCA), yaitu nomor SMSC yang digunakan.

b) Tipe format PDU (Protocol Data Unit) yang digunakan.

c) Message Reference (MR).

d) Destination Address (DA), yaitu berisi nomor tujuan.

e) Protocol Identifier (PID).

f) Data Coding Scheme (DCS) yang menginformasikan enkoding apa yang dipakai oleh MO.

g) Validity Period (VP) memuat informasi berapa lama SMS harus menunggu di antrian, jika nomor tujuan belum memberikan respon. Mirip (tapi tidak sama) dengan TTL (Time To Live) pada TCP/IP.

h) User Data Length (UDL) memuat panjang isi pesan SMS.

i) User Data (UD), pada segmen kesembilan inilah letak isi pesan SMS sesungguhnya berada.

\section{Tabel 3.1 Format Data MO}

\begin{tabular}{|c|c|c|c|c|c|c|c|c|}
\hline SC & PD & M & D & PI & DC & V & UD & U \\
A & U- & R & A & D & S & P & L & D \\
& $\begin{array}{c}\text { Typ } \\
\text { e }\end{array}$ & & & & & & & \\
\hline
\end{tabular}

Setelah pesan MO ini sampai ke SMSC, maka SMSC akan memproses lebih lanjut dengan mengirimkan pesan dengan format MT (Mobile Terminated) ke ponsel tujuan. MT tersebut membawa pesan berisi:

a) Service Center Address (SCA), yaitu nomor SMSC yang digunakan.

b) Tipe format PDU (Protocol Data Unit) yang digunakan.

c) Orginator Address (OA), alamat pengirim.

d) Protocol Indetifier (PID).

e) Data Coding Scheme (DCS) yang menginformasikan enkoding apa yang dipakai oleh MT.

f) Service Center Time Stamp (SCTS) yaitu waktu pengiriman dari SMSC. g) User Data Length (UDL) memuat panjang isi pesan SMS.

h) User Data (UD), memuat isi pesan SMS.

Tabel 3.2 Format Data MT

\begin{tabular}{|c|c|c|c|c|c|c|c|}
\hline SC & PDU & O & PI & DC & SCT & UD & U \\
A & - & A & D & S & S & L & D \\
& Typ & & & & & & \\
& e & & & & & & \\
\hline
\end{tabular}

Pada format MO maupun MT, SMS tidak dikirimkan dalam bentuk teks murni (clear text). SMS menggunakan format data khusus yang dikenal dengan istilah PDU (Protocol Data Unit). PDU sendiri berbentuk oktet (pasangan) heksadesimal dan oktet semidesimal.

\subsection{Akses Telepon Seluler/Handphone menggunakan AT Command}

Untuk memberikan perintah ke telepon selular (ponsel) melalui PC menggunakan perintah AT Command. AT Command adalah perintah-perintah yang digunakan pada telepon selular. AT Command dari tiap-tiap telepon selular (khususnya yang berbeda merk atau pembuatnya) bisa berbeda-beda, tapi pada dasarnya sama. Berikut dibawah ini adalah beberapa AT Command yang digunakan :

a. AT Command untuk Komunikasi Port

AT Command sebenarnya hampir sama dengan perintah > (prompt) pada DOS (Disk Operating System). Perintah-perintah yang dimasukkan ke port dimulai dengan kata AT, lalu kemudian diikuti oleh karakter lainnya yang mempunyai fungsi-fungsi unik. Contohnya : perintah ATE1, digunakan untuk mengetahui status port. Bila status port dalam keadaan siap, maka respon keluaran adalah 'OK'.

b. AT Command untuk Pemilihan SMS Storage AT Command yang digunakan untuk pemilihan SMS 'storage' adalah $\mathrm{AT}+\mathrm{CPMS}=\# \#$, dimana beberapa alternatif dari \#\# adalah :

- ME (Mobile Equipment)

Pemilihan memori handphone sebagai SMS Storage

- SM (SIM Card)

Pemilihan SIM Card sebagai SMS Storage

c. AT Command untuk SMS

Beberapa AT Command yang penting dan sering digunakan untuk SMS adalah sebagai berikut :

- $\mathrm{AT}+\mathrm{CMGS}=\mathrm{n}$

Digunakan untuk mengirim SMS. 
$\mathrm{n}$ = jumlah pasangan heksa PDU SMS dimulai setelah nomor SMS-Centre.

- $\mathrm{AT}+\mathrm{CMGL}=\mathrm{n}$

Digunakan untuk memeriksa SMS.

- $\mathrm{n}=0$ adalah untuk memeriksa SMS baru di inbox

- $\quad \mathrm{n}=1$ adalah untuk memeriksa SMS lama di inbox

- $\mathrm{n}=2$ adalah untuk memeriksa SMS unsent di outbox

- $\mathrm{n}=3$ adalah untuk memeriksa SMS sent di outbox

- $\quad n=4$ adalah untuk memeriksa semua SMS

- $\mathrm{AT}+\mathrm{CMGD}=\mathrm{n}$

Digunakan untuk menghapus SMS.

$\mathrm{n}=$ nomor referensi SMS yang akan dihapus.

d. AT Command untuk Pemilihan Phonebook Telephone

AT Command yang digunakan untuk pemilihan "phonebook telephone" adalah $\mathrm{AT}+\mathrm{CPBS}=\# \#$, dimana beberapa alternatif dari \#\# adalah :

- ME (Mobile Equipment)

Pemilihan memori handphone sebagai Phonebook telephone

- SM (SIM Card)

Pemilihan SIM Card sebagai Phonebook telephone

e. AT Command untuk meng-enable-kan indikator SMS penuh

AT Command yang digunakan untuk mengenable-kan indicator SMS penuh adalah $\mathrm{AT}^{\wedge} \mathrm{SMGO}=\#$, dimana beberapa alternatif dari \#\# adalah :

- 1 adalah untuk meng-enable-kan

- ? adalah untuk menanyakan apakah SMS itu penuh apa tidak.

\subsection{Perangkat Keras}

Perangkat keras untuk prototipe yang dibuat terdiri atas :

1. Mikrokontroler ATMega8535

2. Interfacing Telepon Selular dengan Mikrokontroler

3. Driver Motor DC

4. Rangkaian reset

5. Power Supply

\subsubsection{Mikrokontroler ATMega8535}

Simulasi pengontrolan alat rumah tangga menggunakan SMS ini menggunakan mikrokontroler yang berfungsi sebagai unit pengolah utama atau sebuah CPU pada suatu sistem komputer. Penggunaan mikrokontroler pada alat ini adalah untuk otomatisasi sistem, karena mikrokontroler sudah dilengkapi dengan prosessor, memori internal dan alat input output, sehingga seluruh pemrosesan data dapat dilakukan oleh mikrokontroler.

Mikrokontroler yang digunakan pada prototipe ini adalah mikrokontroler ATMega8535. Sistem minimumnya diperlihatkan pada Gambar 7. Mikrokontroler ini sudah dilengkapi sistem processor 8 bit berbasis RISC (Reduced Instruction Set Computing) dengan kecepatan maksimal 16 MHz. Ukuran memory flash 8KB, SRAM sebesar 512 byte, EEPROM sebesar 512 byte, ADC internal dengan resolusi 10 bit sebanyak 8 channel, port komunikasi serial USART dengan kecepatan maksimal 2.5 Mbps, mode sleep untuk penghematan penggunaan daya listrik.

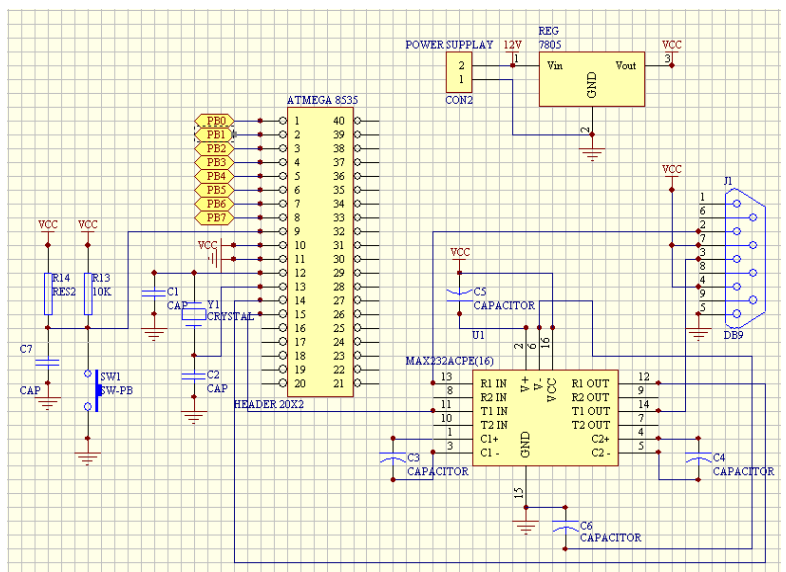

Gambar 7. Sistem Minimum ATMega8535

\subsubsection{Interfacing Telepon Selular dengan Mikrokontroler}

Komunikasi mikrokontroler dengan telepon selular dilakukan secara serial, dengan syarat komunikasi antar mikrokontroler dengan telepon selular adalah harus adanya kesesuaian baud rate antara mikrokontroler dengan telepon selular tersebut yaitu 19200 Kbps. Bentuk antarmuka antara ponsel dengan mikrokontroler diberikan pada Gambar 8 .

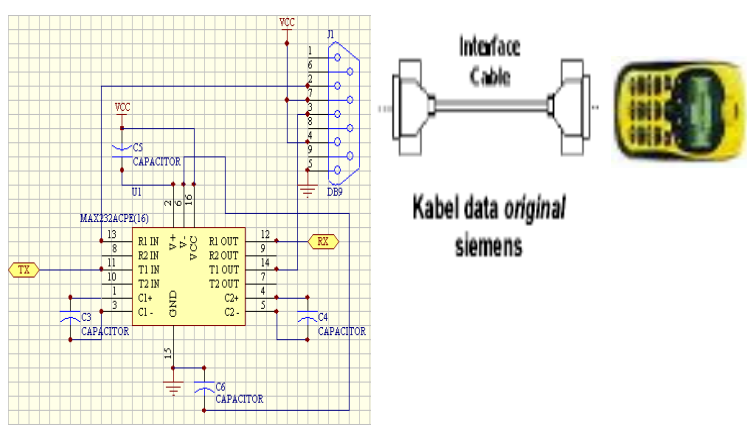

Gambar 8. Antarmuka ponsel dengan mikrokontroler 


\subsubsection{Rangkaian Driver Motor DC}

Rangkaian ini untuk membuka atau menutup pintu gerbang. Disini gerbang menggunakan motor DC untuk memutar motornya, baik secara Clock Wise (CW) atau Counter Clock Wise $(\mathrm{CCW})$. Untuk mengatur pergerakan motor tersebut dibutuhkan sebuah rangkaian driver motor yang dapat mengontrol pergerakan motor DC, dimana instruksi pergerakannya diberikan oleh mikrokontroler sesuai dengan SMS yang diberikan, kemudian diteruskan ke rangkaian driver motor.

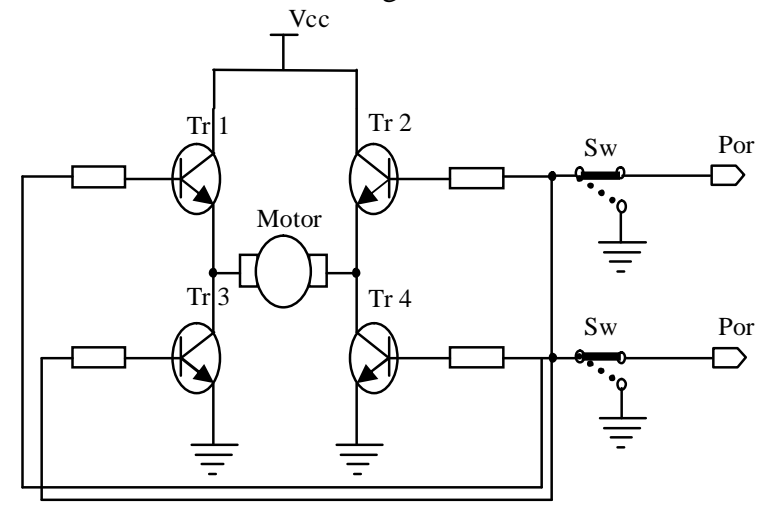

Gambar 9. Rangkaian Driver Motor DC

Rangkaian driver yang diperlihatkan pada Gambar 9 terdiri dari rangkaian transistor yang difungsikan sebagai saklar (switching). Transistor yang digunakan pada rangkaian ini merupakan transistor jenis NPN. Transistor NPN akan aktif apabila kaki basis diberi tegangan positif dan mengalirkan arus dari kolektor ke emiter. Sedangkan apabila basis diberi tegangan negatif maka tegangan tidak DC mengalir dari kolektor ke emiter. Hal ini $12 \mathrm{~V}$ menjadikan transistor berfungsi sebagai saklar (switching) yang menghubungkan kolektor dan emiternya. Apabila salah satu Port B bernilai high maka akan mengaktifkan sepasang transistor yang mengalirkan tegangan pada motor DC dengan polaritas yang berbeda. Perbedaan polaritas pada motor DC akan menyebabkan keterbalikan atau berbeda juga putaran pada motor DC tersebut (kiri / kanan).

\subsubsection{Rangkaian Reset}

Rangkaian reset yang diberikan pada Gambar 10 berfungsi untuk mengembalikan program yang sedang dijalankan mikrokontroler ke posisi awal. Komponen pembentuk rangkaian ini terdiri dari resistor dan sebuah pushbutton.

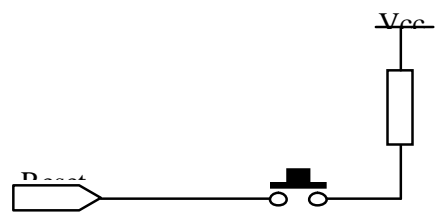

Gambar 10. Rangkaian Reset
Cara kerja dari rangkaian ini adalah saat dilakukan penekanan pada tombol switch maka tegangan sebesar 5 volt akan mengalir dan memicu kaki reset pada mikrokontroler yang akan mengembalikan alamat program sehingga program akan berjalan dari alamat awal lagi. Komponen resistor pada rangkaian ini digunakan untuk membatasi arus yang masuk dari sumber tegangan ke mikrokontroler sehingga jika ada arus lebih yang masuk tidak akan merusak mikrokontroler.

\subsubsection{Rangkaian Power Supply}

Rangkaian power supply merupakan rangkaian pemberi daya bagi prototipe. Komponen utama dari rangkaian ini yaitu IC LM7805 yang merupakan regulator tegangan atau penstabil tegangan. Skematik rangkaiannya diperlihatkan pada Gambar 11. IC ini dapat memberikan output tegangan yang stabil pada tegangan TTL (5 volt) yang sesuai dengan tegangan kerja dari mikrokontroler ATMega8535. Cara kerja rangkaian ini adalah IC LM7805 menerima input tegangan DC (searah) dari sumber tegangan berupa batu baterai atau yang lainnya. Input tegangan ini memiliki cakupan yang cukup luas mulai dari 5 volt hingga 32 volt.

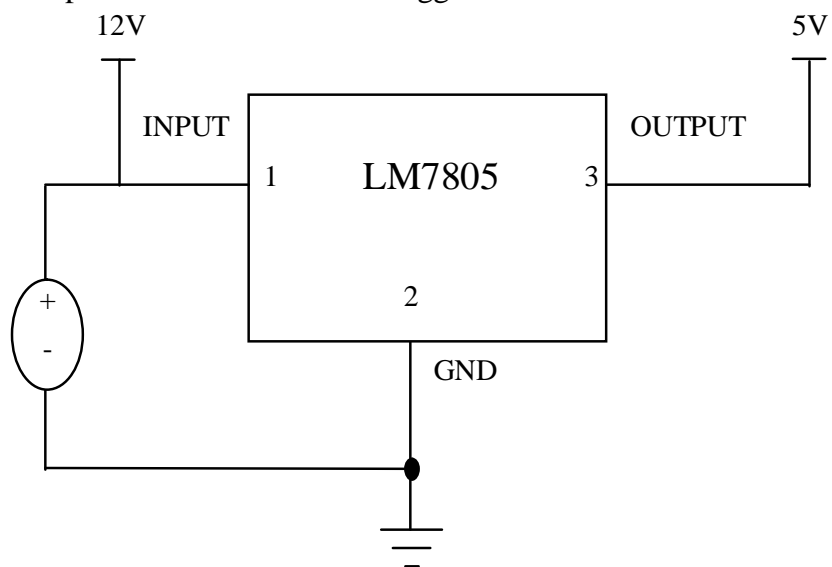

Gambar 11. Rangkaian Power Supply

IC LM7805 akan menstabilkan tegangan input tersebut lalu memberikan tegangan keluaran sebesar 5 volt dan tidak akan berubah meskipun inputnya diberi tegangan yang berbeda-beda. Tetapi pada rangkaian power supply ini kita memakai 2 buah input supply yaitu 5 volt dan juga 12 volt yang digunakan untuk rangkaian driver motor.

\section{PENGUJIAN DAN IMPLEMENTASI}

Setelah melakukan perancangan dan pembuatan alat, maka langkah berikutnya adalah melakukan pengukuran pada blok- blok rangkaian untuk menjamin setiap bagian bekerja sesuai spesifikasi yang diinginkan. Pengujian setiap blok meliputi pengujian mikrokontroler, pengujian perangkat 
lunak yang dibuat, serta integrasi setiap blok sehingga memenuhi tujuan pembuatan prototipe ini.

\subsection{Pengukuran Perangkat Keras}

Pengukuran ini dilakukan pada beberapa bagian yaitu pengukuran pengondisi sinyal tegangan dan frekuensi, level tegangan pada tiap port dari ATmega8535. Pengujian dilakukan dengan cara mengukur output-output per blok subsistem rangkaian.

Pengukuran ini meliputi pengukuran tegangan tiap port ketika ATmega8535 tidak diprogram, diprogram dengan mengeluarkan logika 1 untuk setiap port, diprogram dengan mengeluarkan logika 0 pada tiap port, dan diprogram dengan setiap port dikonfigurasikan sebagai input.

Data pada tabel 3 menunjukan tegangan port ketika ATmega8535 tidak diprogram. Tegangan pada VCC yang terukur $4.92 \mathrm{~V}$.

Tabel 3. Output ATmega8535 Ketika Tidak Diprogram

\begin{tabular}{|c|c|}
\hline PORT & OUTPUT $(\mathrm{V})$ \\
\hline PORTA & 0.19 \\
\hline PORTB & 0.2 \\
\hline PORTC & 0.2 \\
\hline PORTD & 0.2 \\
\hline
\end{tabular}

Tabel 4. Output ATmega8535 Saat Mengeluarkan Logika 1

\begin{tabular}{|l|l|}
\hline PORT & OUTPUT $(\mathrm{V})$ \\
\hline PORTA & 4.92 \\
\hline PORTB & 4.92 \\
\hline PORTC & 4.91 \\
\hline PORTD & 4.91 kecuali PORTD $2=4.90$ \\
\hline
\end{tabular}

Tabel 5. Output ATmega8535 Saat mengeluarkan Logika 0

\begin{tabular}{|l|l|}
\hline PORT & OUTPUT $(\mathrm{V})$ \\
\hline PORTA & 0 \\
\hline PORTB & 0 \\
\hline PORTC & 0 \\
\hline PORTD & 0 \\
\hline
\end{tabular}

Tabel 6. Output ATmega8535 Ketika Dikonfigurasikan Sebagai Input

\begin{tabular}{|l|l|}
\hline PORT & OUTPUT $(\mathrm{V})$ \\
\hline PORTA & 0.28 \\
\hline PORTB & 0.29 \\
\hline PORTC & 0.29 \\
\hline PORTD & 0.29 kecuali PORTD2 $=0$ \\
\hline
\end{tabular}

Pengujian perangkat keras mengikuti gambar 12.

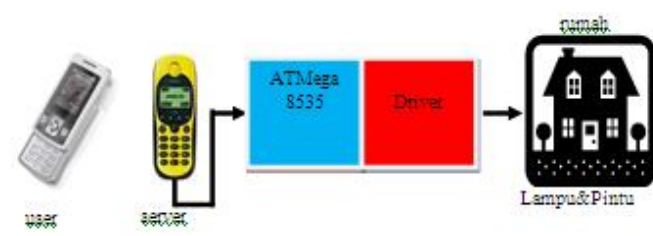

Gambar 12. Skema pengujian prototipe

\subsection{Pengujian Perangkat Lunak}

Perangkat lunak yang digunakan ini menggunakan bahasa pemrograman Code Vision AVR berbasis bahasa $\mathrm{C}$ dan berfungsi melakukan pengendalian terhadap proses kerja mikrokontroler.

Potongan program berikut ini merupakan proses inisialisasi jenis mikrokontroler yang digunakan, jenis bahasa yang digunakan, pendeklarasian variabel dan juga pendeklarasian perintah/command yang sudah di default.

$* * * * * * * * * * * * * * * * * * * * * * * * * * * * * * * * * * * * * * * * *$

$* * * * * * * * * * * * /$

\#include <mega8535.h>

// Standard Input/Output functions

\#include <stdio.h>

\#include <delay.h>

\#define a 15

// Declare your global variables here

flash unsigned char

cmdlist[11][a] $=\{\{$ "EC701B5E8F8162" $\}, \quad / /$ lampu1 1

\{"EC701B5E8F8160"\}, //lampu1 0

\{"EC701B5E978162"\}, //lampu2 1

\{"EC701B5E978160"\}, //lampu2 0

\{"EC701B5E9F8162"\}, //lampu3 1

\{"EC701B5E9F8160"\}, //lampu3 0

\{"E7B79C5C768362"\}, //gorden 1

\{"E7B79C5C768360"\}, //gorden 0

\{"F0B49B5E07C500"\}, //pintu 1

\{"F0B49B5E07C100"\}, //pintu 0

\{"EBB79B9C9EA701"\} \}; //kondisi

unsigned int i,k,digit_no,digit_smsc,temp;

unsigned char

no[30],status[30],isi_sms[91],cmd[a],keluaran,peng irim[30],smsc[30];

bit no_pengirim,new, hasil=0;

Potongan program berikut pada mikrokontroler akan melakukan request/bertanya terhadap telepon selular sever apakah ada SMS baru, jika tidak ada SMS baru mikrokontroler tidak akan melakukan apapun/no operation, dan mikrokontroler akan melakukan pengecekan terus-menerus sampai ada SMS baru (looping). Disini 'AT+CMGL=0' berperan agar mikrokontroler melakukan pengecekan apakah ada sms baru pada telepon selular server. 
void baca_sms()

\{

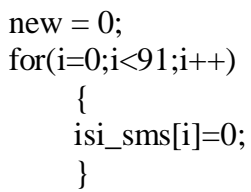

//check

cmd

//putchar(cmd[i]);

//putchar(20);

for $(\mathrm{i}=0 ; \mathrm{i}<30 ; \mathrm{i}++)$

\{

\}

pengirim $[\mathrm{i}]=0$;

for $(\mathrm{i}=0 ; \mathrm{i}<$ digit_no; $\mathrm{i}++)$

\{ pengirim[digit_no-1-

i]=isi_sms[temp-39-i];

$$
\text { \} }
$$

Potongan program selanjutnya pada mikrokontroler akan melakukan perbandingan

$/ /$ check dengan hasil SMS yang didapat. Apakah isi pesan (SMS) tersebut sesuai dengan perintah/command yang diberikan atau tidak.

void compare cmd()

\{

//printf("ini compare comand, cmdnya $\%$ s",cmd);

for $(\mathrm{k}=0 ; \mathrm{k}<11 ; \mathrm{k}++)$

\{

for $(\mathrm{i}=0 ; \mathrm{i}<\mathrm{a}-1 ; \mathrm{i}++)$

\{

if $(100+\mathrm{cmd}[\mathrm{i}]-\mathrm{cmdlist}[\mathrm{k}][\mathrm{i}]==100)$ hasil $=1$;

else

\{

hasil=0;

$\mathrm{i}=\mathrm{a}$;

\}

\}

if (hasil==1)

\{

keluaran $=\mathrm{k}$;

$\mathrm{k}=12$;

\}

else

\#asm("nop")

\}

if $(\mathrm{k}==11)$

keluaran $=11$;

//printf("keluaran nya : \%i ",keluaran);

\}

Pada potongan program selanjutnya mikrokontroler akan melakukan perbandingan dengan nomor pengirim/client. Apakah nomor pengirim/client ini adalah nomor yang authorize/nomor yang diizinkan untuk pengontrolan alat ini. Tetapi potongan program ini berlaku jika, perbandingan hasil isi pesan (SMS) nya telah sesuai dengan perintah/command yang berlaku untuk pengontrolan alat ini.

void compare_no()

\{ I /printf("ini compare no, ");

for(i=0;i<digit_no;i++) \}

else

\{

no_pengirim $=0 ; \quad / / \mathrm{No}$ Salah

$\mathrm{i}=$ digit_no;

//printf("no pengirim salah "); \}

\} 
Pada potongan program berikut ini, mikrokontroler akan melakukan atau melaksanakan sesuai dengan perintah dari isi pesan (SMS) dari nomor pengirim/client yang telah diizinkan. Pada PORTB.(n) akan bernilai satu (high) yang mengidentifikasikan bahwa lampu pijar maupun driver motor akan bekerja. Simulasi untuk lampu menggunakan PORTB.0, PORTB.1, dan PORTB.2, sedangkan pintu memanfaatkan 2 buah PORTB yaitu PORTB.5, PORTB.6. Potongan program berikut ini akan menyimpan kondisi terakhir PORT OUTPUT yang akan disimpan di phonebook ke 2 dengan nama status akhir. Disini ' $\mathrm{AT}+\mathrm{CPBW}=2$ ' berperan untuk menulis kembali nomor telepon di phonebook ke 2 sebagai status akhir.

void eksekusi()

$\{\quad / /$ printf("ini eksekusi, keluarannya $\%$ i",keluaran);

PORTB. $7=1$; Sesuai

if (no_pengirim $==1$ ) $/ / \mathrm{Jika}$ no Pengirim

\{

switch (keluaran)

\{

case 0 :

PORTB. $0=1$;

status_ahir();

kirim_status();

if(getchar()!='K')

\{

delay_ms(100);

kirim_status();

\}

break;

case 1:

PORTB. $0=0$;

status_ahir();

kirim_status();

if(getchar()!='K')

\{

delay_ms(100);

kirim_status();

\}

break;

case 2:

PORTB. $1=1$;

status_ahir();

kirim_status();

if(getchar ()$\left.!=' K^{\prime}\right)$

\{

delay_ms(100);

kirim_status();

\}

break;

case 3:

PORTB. $1=0$;

status_ahir();

kirim_status();
if(getchar()!='K')

\{

delay_ms(100);

kirim_status();

break;

case 4:

PORTB. $2=1$;

status_ahir();

kirim_status();

if(getchar()!='K')

\{

delay_ms(100);

\}

kirim_status();

break;

case 5:

PORTB. $2=0$;

status_ahir();

kirim_status();

if(getchar()!='K')

\{

delay_ms(100);

kirim_status();

break;

case 6:

PORTB. $3=1$;

PORTB.4=0;

status_ahir();

kirim_status();

if(getchar()!='K')

\{

delay_ms(100);

kirim_status();

\}

break;

case 7:

PORTB. $3=0$;

PORTB.4=1;

status_ahir();

kirim_status();

if(getchar()!='K')

delay_ms(100);

kirim_status();

\}

break;

case 8:

PORTB. $5=1$;

PORTB. $6=0$;

status_ahir();

kirim_status();

if(getchar()!='K')

\{

delay_ms(100);

kirim_status();

break;

case 9: 


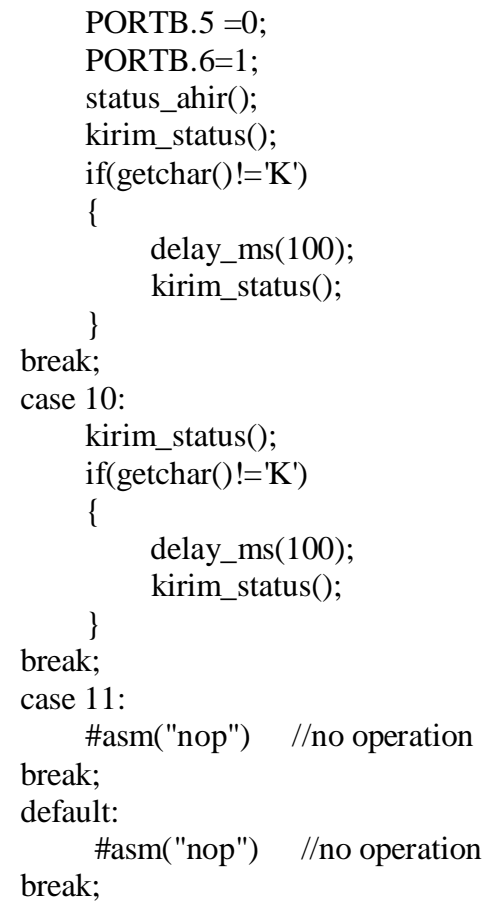

PORTB. $5=0$;

PORTB. $6=1$;

status_ahir();

kirim_status();

if(getchar()!='K')

\{

delay_ms(100);

kirim_status();

\}

break;

case 10:

kirim_status();

if( getchar()!='K')

\{

delay_ms(100);

kirim_status();

\}

break;

case 11: break;

\#asm("nop") //no operation

default: break;

\#asm("nop") //no operation

Dari hasil perancangan dan pengujian setiap bagian maka langkah berikutnya adalah mengintegrasikan menjadi satu kesatuan prototipe sesuai yang diinginkan. Gambar 13 memperlihatkan prototipe yang dibuat dalam bentuk miniatur rumah.

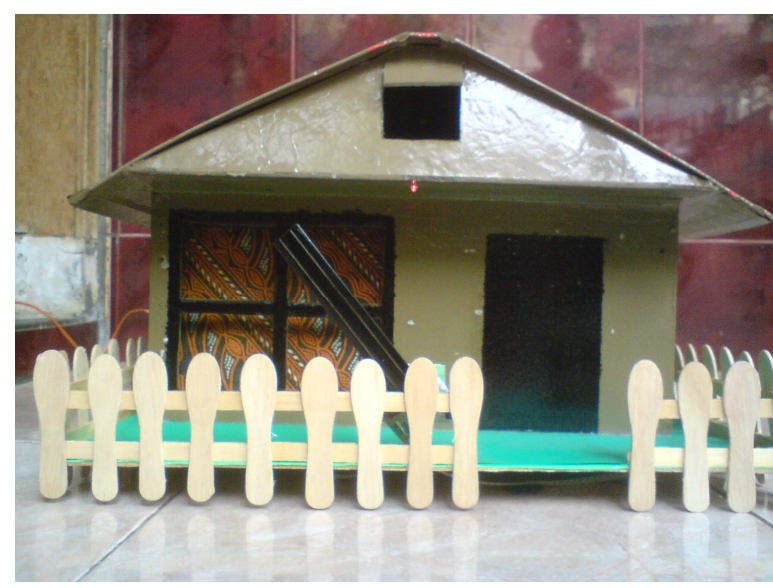

Gambar 13. Miniatur rumah

Realisasi perangkat kerasnya diperlihatkan pada gambar 14. Sebuah ponsel bercasing biru yang terletak paling bawah di gambar tersebut berfungsi sebagai server yang ditempatkan di rumah, sedangkan ponsel lainnya adalah ponsel yang dipegang oleh pengguna.

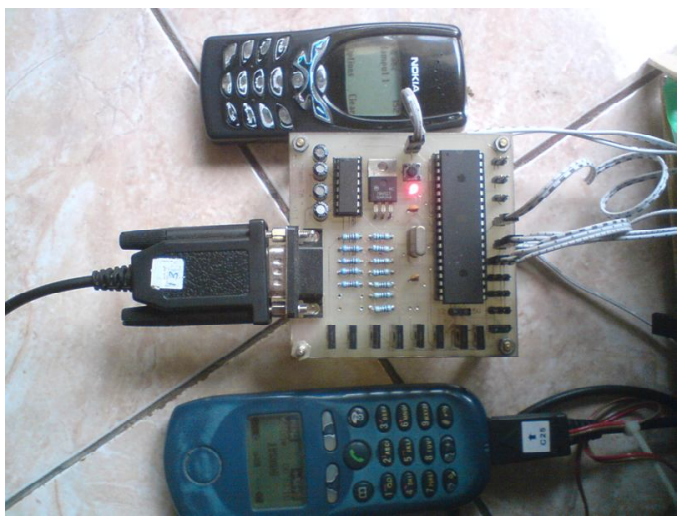

Gambar 14. Realisasi perangkat keras

\section{KESIMPULAN}

Hasil pengujian memperlihatkan bahwa prototipe ini berfungsi dengan baik yang diperlihatkan dengan kemampuan mengatur pintu gerbang dan lampu pijar menggunakan pesan singkat yang dikirim dari ponsel pengguna. Karena jaringan komunikasinya menggunakan jaringan publik maka kualitas pengaturannya sangat tergantung pada kualitas sinyal. Sebagai tindak lanjut dari penelitian ini adalah dengan menambahkan sistem alarm dan kompleksitas tugas yang harus dikerjakan dibuat sedekat mungkin dengan kebutuhan terhadap pengamanan rumah atau gedung menuju otomasi gedung.

\section{DAFTAR PUSTAKA}

Nalwan, P. A., Teknik Antar Muka dan Pemrograman Mikrokontroller Atmega 8535, PT. Elex Media Komputindo, 2003.

Putra, A. E., Belajar Mikrokontroller Atmega8535, Penerbit Gava Media, Yogyakarta, 2002.

Selian, A., 3G Mobile Licensing: From GSM to IMT2000- A Comparative Analysis, ITU Report, 2001.

Soesetijo, S., SMS, EMS, dan MMS, diambil dari http://memomu.blogspot.com/2008_02_01_archive. html hari Jum'at, 3 Juni 2011 pukul 09.00 WIB.

Stallings, W., Wireless Communication and Networks - 2nd edition, Prentice Hall, New Jersey, 2005.

Sutrisno, Elektronika : Teori dan Penerapan, Penerbit ITB, Bandung, 1986. 
Wikipedia, Global System for Mobile Communications, diambil dari http://en.wikipedia.org/wiki/GSM hari Kamis, 9 Juni 2011, pukul 11.00 WIB

-------, RS-232 Data Interface, diambil dari http://www.arcelect.com/rs232.htm hari Kamis, 26 Agustus 2010 pukul 10.00 WIB

------, ATMega8535 Controller, diambil dari http://www.futurlec.com/ATMEGA8535_Controlle

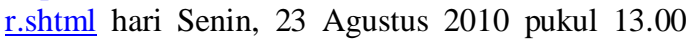
WIB

\section{BIOGRAFI SINGKAT}

Asep Najmurrokhman adalah dosen tetap di Jurusan Teknik Elektro Universitas Jenderal Achmad Yani beralamat di Jl. Trsn Jend. Sudirman PO Box 148 Cimahi 40533 Telp. 0813-21815649.

Tedi Muslim adalah alumnus Jurusan Teknik Elektro Universitas Jenderal Achmad Yani yang bekerja di perusahaan telekomunikasi. 